\title{
What's accepted is not always appropriate!
}

\author{
Leslee J. Shaw, $\mathrm{PhD}^{\mathrm{a}}$ \\ a Emory University School of Medicine, Atlanta, GA
}

Received Jul 18, 2017; accepted Jul 18, 2017

doi: 10.1007/s12350-017-1007-8

\section{See related article, pp. 2044-2052}

Implementation of quality standards for cardiac imaging has been a goal of recent initiatives including the evidence-based indications for referral to stress myocardial perfusion imaging. These referral indications have been summarized in recent appropriate use statements from the American College of Cardiology (ACC) and American College of Radiology (ACR). ${ }^{1,2}$ In this issue of the Journal of Nuclear Cardiology, ${ }^{3}$ Bagrova and colleagues provide a comparison of the concordance between appropriate use indications based on published statements from the ACC and ACR. This is one of a series of reports from this group on the utility of appropriate use criteria in guiding optimal referral patterns to stress myocardial perfusion imaging. ${ }^{3-7}$ In this report, the authors report that there was poor concordance between appropriate use criteria developed by the ACC as compared to the ACR, with a kappa statistic of 0.32 - supporting modest agreement between the two statements. As there is no definitive "gold standard" for appropriate indications, this finding of modest concordance is reason for caution and pause as to whether variability in practice patterns will be observed. The importance of this finding relates to the upcoming Medicare requirements that an ordering physician consult with an appropriate use criteria statement by means of a qualified decision support mechanism beginning in 2019.

A major challenge with all medical procedures is the marked variability in use across this country. The variability is use which does not appear to be driven by clinical risk within a given population. ${ }^{8}$ Based on the current report, referral patterns may vary based on

\footnotetext{
Reprint requests: Leslee J. Shaw, PhD, Emory University School of Medicine, Atlanta, GA; lshaw3@emory.edu J Nucl Cardiol 2018;25:2056-7. $1071-3581 / \$ 34.00$

Copyright (c) 2017 American Society of Nuclear Cardiology.
}

whether the ACC or ACR statement is consulted. A primary benefit of this new regulation relying on appropriate use criteria is that standardized referral patterns may ensue. The hope for our overburdened physicians is that prior authorization mechanisms, in place to reduce inappropriate testing and enhance cost savings, may become eliminated. However, variability between the ACC and ACR statements may further contribute to variability and fail to produce the uniformity in referral patterns or be as effective at reducing unnecessary testing.

These questions based on the intriguing findings from this report by the Winchester group ${ }^{3}$ should prompt additional thoughts as to how we can promote uniformity and reduce wide variability in current referral practices for stress myocardial perfusion imaging and other cardiac imaging procedures. I might also suggest that within the imaging community we should be devising broader strategies around driving quality and not solely a preservation of utilization. A focus on collaborative statements should be an important goal for all cardiovascular imagers including radiologists, nuclear medicine physicians, and cardiologists. Harmony across the indications and an improved data synthesis to highlight evidentiary standards for nuclear cardiology represent important next steps in created quality imaging practices.

Moreover and importantly, these indications require more rigorous evaluation than the data currently support. Does the use of appropriate use criteria improve patient selection? Do they enhance disease detection and, ultimately, improve patient care? Should we mandate clinical trials which support appropriateness-criteria-led strategies as compared to standard testing approaches (without the use of appropriateness criteria)? In one recent example of a guideline-directed strategy of care compared with stress myocardial perfusion imaging and cardiovascular magnetic resonance (CMR) imaging, the Clinical Evaluation of Magnetic Resonance Imaging in Coronary Heart Disease 2 (CE-MARC 2) trial revealed that the United Kingdom's guideline for stable chest pain was less effective and with higher rates of unnecessary coronary angiography when compared to stress CMR or nuclear imaging. ${ }^{9}$ Although this example of the 
CE-MARC trial may be imperfect, it does suggest that challenging current healthcare regulations remains an important mission within the cardiovascular community. In the case of the appropriate use criteria, who among us will take the lead?

\section{Disclosure}

Author has nothing to disclose.

\section{References}

1. Wolk MJ, Bailey SR, Doherty JU, Douglas PS, Hendel RC, Kramer CM, Min JK, Patel MR, Rosenbaum L, Shaw LJ, Stainback RF, Allen JM, American College of Cardiology Foundation Appropriate Use Criteria Task F. ACCF, AHA, ASE, ASNC, HFSA, HRS, SCAI, SCCT, SCMR, STS 2013 multimodality appropriate use criteria for the detection and risk assessment of stable ischemic heart disease: A report of the American College of Cardiology Foundation Appropriate Use Criteria Task Force, American Heart Association, American Society of Echocardiography, American Society of Nuclear Cardiology, Heart Failure Society of America, Heart Rhythm Society, Society for Cardiovascular Angiography and Interventions, Society of Cardiovascular Computed Tomography, Society for Cardiovascular Magnetic Resonance, and Society of Thoracic Surgeons. J Am Coll Cardiol. 2014;63:380-406.

2. Woodard PK, White RD, Abbara S, Araoz PA, Cury RC, Dorbala S, Earls JP, Hoffmann U, Hsu JY, Jacobs JE, Javidan-Nejad C, Krishnamurthy R, Mammen L, Martin ET, Ryan T, Shah AB, Steiner RM, Vogel-Claussen J, White CS. ACR appropriateness criteria chronic chest pain-low to intermediate probability of coronary artery disease. J Am Coll Radiol. 2013;10:329-34.
3. Bagrova A, Alsamarah AY, Winchester DE. Comparing two methods for determining appropriateness of myocardial perfusion imaging: Criteria from the American College of Cardiology Foundation and The American College of Radiology. J Nucl Cardiol 2017.

4. Winchester DE, Wolinsky D, Beyth RJ, Shaw LJ. Discordance between appropriate use criteria for nuclear myocardial perfusion imaging from different specialty societies: A potential concern for health policy. JAMA Cardiol. 2016;1:207-10.

5. Winchester DE, Meral R, Ryals S, Beyth RJ, Shaw LJ. Appropriate use of myocardial perfusion imaging in a veteran population: Profit motives and professional liability concerns. JAMA Intern Med. 2013;173:1381-3.

6. Kline KP, Plumb J, Nguyen L, Shaw LJ, Beyth RJ, Huo T, Winchester DE. Patient and provider attitudes on appropriate use criteria for myocardial perfusion imaging. JACC Cardiovasc Imaging. 2017;10:824-5.

7. Elgendy IY, Mahmoud A, Shuster JJ, Doukky R, Winchester DE. Outcomes after inappropriate nuclear myocardial perfusion imaging: A meta-analysis. J Nucl Cardiol. 2016;23:680-9.

8. Mark DB, Anderson JL, Brinker JA, Brophy JA, Casey DE Jr, Cross RR, Edmundowicz D, Hachamovitch R, Hlatky MA, Jacobs JE, Jaskie S, Kett KG, Malhotra V, Masoudi FA, McConnell MV, Rubin GD, Shaw LJ, Sherman ME, Stanko S, Ward RP. ACC/AHA/ ASE/ASNC/HRS/IAC/Mended Hearts/NASCI/RSNA/SAIP/SCAI/ SCCT/SCMR/SNMMI 2014 health policy statement on use of noninvasive cardiovascular imaging: A report of the American College of Cardiology Clinical Quality Committee. J Am Coll Cardiol. 2014;63:698-721.

9. Greenwood JP, Ripley DP, Berry C, McCann GP, Plein S, Bucciarelli-Ducci C, Dall'Armellina E, Prasad A, Bijsterveld P, Foley JR, Mangion K, Sculpher M, Walker S, Everett CC, Cairns DA, Sharples LD, Brown JM, Investigators C-M. Effect of care guided by cardiovascular magnetic resonance, myocardial perfusion scintigraphy, or NICE guidelines on subsequent unnecessary angiography rates: The CE-MARC 2 randomized clinical trial. JAMA. 2016;316:1051-60. 